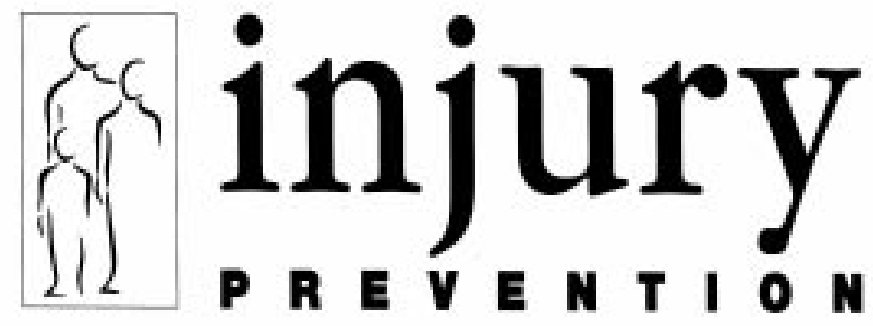

\title{
Editorials
}

\section{Killing speed}

"Speed kills. Kill your speed". This clever message has appeared in the media in the UK for several years. Other countries use similar phrases. Although brief, all the essential ideas are represented. They state the problem and offer a solution. In this respect, it is a model safety message. But the question to be asked of it, as of any other preventive measure, is: does it work? Is there good evidence that drivers have slowed down?

I acknowledge being preoccupied by speeding cars in part because I bicycle to work. Speeders are part of every trip and I occasionally see the grim consequences of their behaviour. In vain, I shake my fist and shout at the violators but it seemed that writing this might be more effective and safer. After deciding to do so, however, I discovered that I had been scooped by an editorial in the BMF. ${ }^{1}$ The author does such a good job of summarizing the main points that I quote him extensively and shamelessly. Moreover, if memory serves I have editorialized on this before and may at times be quoting myself. In any case, I make no apologies for doing so again, such is the importance of this problem. It is the same everywhere in the world, affecting all age groups. (I do apologize, however, for drawing almost exclusively on material from the UK. It just so happens to come in a readily available form.)

\section{The problem}

Numerous studies show the relation between car speed and injury. The "kill your speed" message originates with the estimate that "the chance of a pedestrian [or cyclist, presumably] being seriously injured or killed if struck by a car is $45 \%$ at $30 \mathrm{mph}$ and $5 \%$ at $20 \mathrm{mph}$. ${ }^{1}$ Other studies indicate that someone hit by a car travelling at $35 \mathrm{mph}$ is more than twice as likely to be killed than if the vehicle had been moving at $30 \mathrm{mph}$. The original data are cited in a UK road safety strategy document issued in $1997 .^{2}$ Another frequently cited study suggests that for every mile per hour reduction in average speed there is an $8 \%$ reduction in fatal injuries. ${ }^{3}$

Although to the best of my knowledge neither study is based on solid empirical data, their credibility rests on elementary physics. A 2000 pound object moving at 20 mph hits a stationary object with a decelerating force of 40000 Newtons (mass $\times$ deceleration). In this it is assumed that what is being hit-a pedestrian or bicyclistis, effectively, stationary. Highway crashes, however, rarely involve immobile objects. Even hitting a barrier or median is not necessarily as grim as might be expected because modern highway engineering incorporates some yield in these structures. Many other motorway collisions involve striking a car in motion, and except for head-on crashes, the direction of collision makes the physics complex. The point is that injuries to most occupants in highway collisions are often less severe than those involving urban pedestrians. But even on highways speed is the main predictor of what happens in a crash because, other than monster sports utility vehicles or trucks, most cars weigh roughly the same. Thus, the bottom line: the greater the speed, the greater the damage. Beyond any reasonable doubt, speed kills.

\section{The solution}

We need not spend much energy (no pun intended) on the second part of the message; it is a direct corollary of the first part. If speeding is the problem, driving more slowly is the solution.

\section{How good is the message?}

It seems unlikely that in this instance as in so many others, the message alone persuades drivers to slow down. Recent studies show no indication of a decrease in average speeds either on highways or in urban areas. The UK Kill Your Speed Campaign web site states that seven out of 10 drivers regularly break the $30 \mathrm{mph}$ speed limit. ${ }^{4}$ It adds that two thirds of all "accidents" in which people are killed or injured happen in areas with a $30 \mathrm{mph}$ limit. These were figures before the campaign began, but recent reports indicate little change. A comprehensive study into driver habits indicated that $10 \%$ exceed the $30 \mathrm{mph}$ speed limit by at least $10 \mathrm{mph}$, apparently undeterred by the risk of a $£ 40$ penalty. Most of the 3.2 million motorists recorded during a 28 day investigation at 10 sites drove above $35 \mathrm{mph}$, the minimum speed that usually triggers a fine. Some drivers were recorded by automatic detection equipment travelling at more than $70 \mathrm{mph}$ in a $30 \mathrm{mph}$ area. Clearly, the message alone has not been effective.

\section{Making the message work}

An important exception to this depressing picture is found in communities that have adopted $20 \mathrm{mph}$ limits. A review cited by Pilkington ${ }^{1}$ showed that $20 \mathrm{mph}$ zones had average speed reductions of $9.3 \mathrm{mph}$ and that this was associated with a $60 \%$ reduction in traffic "accidents". ${ }^{5}$ Moreover, he notes that the $20 \mathrm{mph}$ policy has wide public support, at least in London. ${ }^{1}$ So the question now arises: why is this not mandatory country-wide, and indeed, why doesn't every country impose such restrictions?

I have a hunch that part of the answer is that few drivers associate the word "speed" in the message with the usual speed at which they travel. Some may not even associate it 


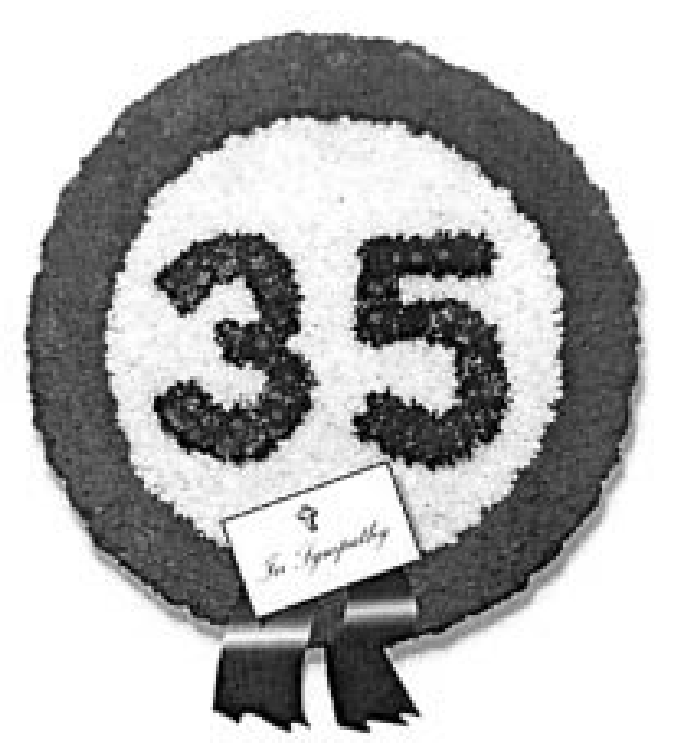

At $35 \mathrm{mph}$ you are twice as likely to kill someone as you are at $30 \mathrm{mph}$.

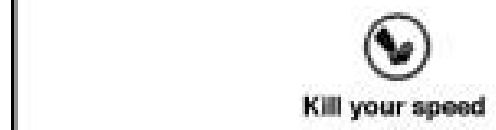

Poster from the Department of the Environment, Transport and the Regions Kill Your Speed Campaign.

with doing $40 \mathrm{mph}$ in a $20 \mathrm{mph}$ zone. The average motorist thinks speeding means hitting $100 \mathrm{mph}$ on a highway posted at $65 \mathrm{mph}$. However, many more lives would be saved by lower limits rigidly enforced in urban areas than if an equivalent effort were to be focussed on highway travel. There are two reasons: first, the victim in urban areas is usually an unprotected pedestrian or bicyclist (like me); second, there are more cars and more potential victims in urban areas. This fits with the late Geoffrey Rose's arguments that population based strategies for prevention are more effective than those focussing on high risk groups. A general slowing of traffic everywhere, but especially in urban areas, would have greater benefits than trying to catch drivers racing along highways at $100 \mathrm{mph}$ and more. This is so because cities include much more of the most vulnerable population. UK estimates are that eight times as many people die each year on rural roads as on motorways. The same ratio applies when using accidents per vehicle kilometre travelled.

Experts continue to debate whether slowing highway traffic is possible, highly beneficial, or cost effective. Many studies suggest that slower speeds resulting from the oil embargo in the mid-70s reduced fatalities. Others (for example, Gullon ${ }^{6}$ ) sharply disagree, arguing that the decline in deaths had more to do with the business cycle, possibly mediated through driver distraction. However, the evidence for $20 \mathrm{mph}$ limits in urban areas, combined with speed cameras ${ }^{7}$ and harsh penalties, is compelling.

Equally persuasive are empirical data showing the devastating consequences of speeding. A recent study using a case-control design, shows that " $68 \%$ of casualty crash cars were exceeding $60 \mathrm{~km} / \mathrm{h}$ compared to $42 \%$ of those not involved in a crash". ${ }^{8}$ The authors conclude that $46 \%$ of speed casualty crashes probably would have been avoided, or reduced to non-casualty crashes, if none of the case vehicles had been travelling above the speed limit. Stated differently, they note that "in a $60 \mathrm{~km} / \mathrm{h}$ speed limit area, the risk of involvement in a casualty crash doubles with each $5 \mathrm{~km} / \mathrm{h}$ increase in travelling speed above 60 $\mathrm{km} / \mathrm{h}$ ". (And, in a fascinating aside, the authors equate the risk of speeding with that of alcohol, and ruefully observe that the former only receives a $\$ 110$ fine while the latter gets a $\$ 500-\$ 900$ fine and automatic license disqualification for at least six months.)

A study in the US examined child pedestrian injuries on residential streets and concluded that after controlling for many other factors the essential variable is speed. ${ }^{9}$ Estimates from this study are that an increase in average speed from $20-30 \mathrm{mph}$ is associated with 7.6 times the risk of pedestrian injury.

\section{Political considerations ${ }^{10}$}

For a while it appeared that the Transport Minister in the UK was poised to introduce a policy of zero tolerance of speeding. He then backed off under pressure from various sources, including the motorist lobby. Although not as pernicious as the gun or cigarette lobby, it is just as powerful in most countries. For example, the Automobile Association said it would support strict enforcement of the law (only) if road signs made it obvious that the limit was in force. A senior Tory stated, "Motorists who are generally law-abiding will not take kindly to longer journey times and a guaranteed fine every time they accidentally creep over the speed limit". The government was also reportedly nervous about being seen to be "anticar". "John Prescott would do well to remember that the frustration caused by slow-moving traffic can make drivers angry - and this can lead to foolish decisions. It would do nothing to improve safety on our roads", said the Shadow Home Secretary.

Another excuse for not following through with the crackdown was that police lacked the resources to enforce these limits that are "too low". But new policies to permit police to keep some of the share of ticketing would increase resources and allow them, for example, to invest in roadside cameras.

\section{Bottom lines}

A spokesperson for the Institute of Advanced Motorists, says speeding is endemic. "Most people see it as a minor infringement. The government's efforts to improve road safety need to render speeding as antisocial as drinkdriving is now". The Home Office Minister agreed that " 30 means 30 " and added that the best way to ensure that the law was respected was to enforce it.

It is estimated that road deaths and serious injuries could be halved if $20 \mathrm{mph}$ limits were introduced in built-up areas but a spokesperson for Transport 2000 said the measures would not go far enough and the director of the Pedestrians Association, said: "The question of speed limits is too important to be left to local authorities".

The last words are those of the Prime Minister: "We have the second best safety record in Europe, but the fact that 15 children are killed or seriously injured on our roads every day is simply unacceptable". He added: "We will target accident hotspots around schools, improve driver training, and how we teach our children about safety on roads. Our $50 \%$ child casualty reduction target is a tough one. It will take a huge effort to meet it, but I believe we can". 
1 Pilkington P. Reducing the speed limit to $20 \mathrm{mph}$ in urban areas. $B M \mathcal{F}$ 2000;320:1160.

Department of the Environment, Transport and the Regions. Road safety strategy: current problems and future solutions. London: DETR, 1997.

US Department of Transport. National maximum speed limits: fiscal year 1993. Washington, DC: Department of Transport, 1995

4 Department of the Environment, Transport and the Regions. "Kill your speed" campaign web site. www.detr.gov.uk/campaigns/kys99/

5 Department of the Environment, Transport and the Regions. Review of traffic calming schemes in $20 \mathrm{mph}$ zones. London: DETR, 1996.

6 Gullon AC. Autobahn fatality rates and general speed limits: what really happened in 1973/74? SAE Technical Paper Series 970280. Reprinted from: Progress with human factors in automotive design: seating comfort, visibility, and safety. 1997.

7 West R. The effect of speed cameras on injuries from road accidents. BMF 1998;316:5-6.

8 Travelling speed and the risk of crash involvement: executive summary. http://plato.raru.adelaide.edu.au/speed/

9 Jacobsen P, Anderson CL, Winn DG, et al. Child pedestrian injuries on residential streets: implications for traffic engineering. ITE Journal on the web: February 2000:71-5.

10 Various sources, mostly provided by Geraint Jennings on Pednet-for example, BBC News, the Times, the Guardian.

\section{Enlightening the cost of injury debate}

In the Opinion-Dissent columns of this issue, the contributors debate about the usefulness of cost of injury (or illness) studies that lack evidence of effectiveness. The arguments on each side are so well formulated that I will not venture to offer a personal opinion about which is right. But I have always been intrigued by the metaphysical challenge that health economists face when trying to place value on human life - an essential component of any such study.

We use many techniques to accomplish this seemingly impossible task. I recently encountered one approach that has probably not received much attention. The details are in Leviticus, chapter XXVII. "And the Lord spoke unto Moses saying: Speak unto the children of Israel, and say unto them: When a man shall clearly utter a vow of persons unto the Lord [this is interpreted as part of the process of setting a valuation upon oneself or one's family when making a pledge to God], then thy valuation shall be for the male from twenty years of even unto sixty years old, even thy valuation shall be fifty shekels of silver ... and if it be a female, then thy valuation shall be thirty shekels". The quotation continues, designating specific amounts depending on the age group, with a consistent gender bias suggesting that males of whatever age are worth approximately twice that of females. It is also noteworthy that the young and the old are valued less than those 20-60 years of age. The footnote explains that "the valuation seems to have been made on the basis of what might be called the market value of the individual's labour. A woman, not possessing the physical strength of a man, had a lower valuation set upon her".

My intention is not to foment further debate about sexism in the Bible, but to remind our debaters and other scientists that there is truly little new under the sun.

I B PLESS

Editor

\section{Guest editorial}

\section{Preventing school violence: a time for hard, solid thinking}

On my office wall hang several quotes from the Rev Dr Martin Luther King, Jr. That is probably not surprising, considering that much of my work involves youth violence prevention. No one in American history has spoken more passionately or eloquently than Dr King on the evils of violence. One of the quotes from Dr King on my wall, however, is not found in books of famous quotations, nor has it become part of the lexicon of American history as have so many of his words. Yet, as I work on youth violence prevention, this is often the quote I find most inspirational:

"Rarely do we find men who willingly engage in hard, solid thinking. There is an almost universal quest for easy answers and half-baked solutions. Nothing pains some people more than having to think".

At times of crises, it is especially important to listen to Dr King's message. For US schools, never had there been a crisis on the scale of what happened in Columbine High School last year. On 20 April 1999, two students at this high school in Colorado killed 12 students and one teacher and injured 21 others, before committing suicide. This followed several school shootings during the previous school year. After the tragedy at Columbine, parents, government officials, and the news media called for immediate solutions to school violence. Proposed solutions included restricting access to campuses so that students and others could not enter or leave during the school day, posting armed police officers in schools, increasing the use of metal detectors, tightening gun control legislation, and trying young perpe- trators in adult courts. Loud cries were heard for the development of "warning signs" to identify students who might perpetrate such crimes in the future. Security companies began offering their services to "profile" potential school shooters.

It is understandable that the public would want easy answers and quick solutions in the face of extreme violence such as that at Columbine. We all are concerned for the safety of children at school. But as scientists concerned about young people, it is our responsibility to do hard, solid thinking rather than accept these easy and quick solutions. To implement solutions that work, we must first understand the nature of school violence and the characteristics of effective interventions.

The problem is more one of youth violence than school violence. While school shootings like the one at Columbine High School have increased public attention to violence associated with schools, the fact remains that most American schools are safe places. Less than $1 \%$ of all homicides and suicides among school aged children (5-19 years of age) occur at school or on the way to or from school. ${ }^{1}$ None the less, homicide is not rare among American children. It is the fourth leading cause of death among Americans aged 10-14 years and the second leading cause of death among those aged 15-24 years. In 1997, 283 children aged 10-14 years and 6146 adolescents aged $15-24$ years were murdered. The US child homicide rate, 2.57/100 000 for 
children under 15 years of age, is five times that of 25 other industrialized countries combined. ${ }^{2}$

Violence is not amenable to easy or quick solutions. Behavioral, biological, social, and environmental factors all are associated strongly with the development of violent behavior. These factors have been addressed, using many primary and secondary prevention approaches, by the fields of criminal justice, social services, mental health, education, social sciences, and public health. No single discipline alone can prevent violence. A complex problem such as violence must be prevented through a combination of approaches.

In the week after the shootings at Columbine High School, US government agencies met to develop a coordinated research agenda for youth violence prevention. At the same time, agency staff working on youth violence prevention were inundated with urgent requests from higher ranking officials, legislators, the press, and the public for new projects, studies, and announcements regarding school violence. It soon became clear that no one understood what each agency was already doing to address youth violence. Without this knowledge it was impossible to prevent duplicative work, create new partnerships, or develop better interventions.

As a result of the meeting, an inventory of federal activities that address violence in schools was developed. Each agency listed its activities related to school violence and recommended other agencies to contact for additional activities. The agencies described activities that directly seek to prevent or respond to violence that occurs on school property, on the way to or from school, or at school related events. They also described activities that indirectly address school violence by focusing on precursors of violence, factors associated with violence, or mechanisms for preventing violent behavior.

The inventory includes more than 100 activities involving some 10 federal departments and more than 25 agencies including those targeting health, mental health, education, justice, labor, and housing and urban development. The activities are grouped into several categories: surveillance, evaluation research, other research, research synthesis, programmatic activities, resources, and technical assistance centers. The inventory was published in April 2000 in the Fournal of School Health ${ }^{3}$ and posted on the Centers for Disease Control and Prevention (CDC) web site at: www.cdc.gov/nccdphp/dash/violence/index.htm. Schools, community groups, national organizations, and state and local agencies can use the inventory to find school violence prevention resources and to get accurate information about federal violence prevention and research activities.

By describing the breadth and depth of current activities, the inventory may provide a base for planning future violence prevention research and practice. A wide variety of activities are under way. The sponsoring agencies understand that these activities might generate a greater return on investments if funds were pooled rather than used for multiple similar interventions. Fewer than one third of the projects listed in the inventory name collaborators. Most collaborations involve sharing advice, information, data, or access to constituents. Only a few projects involve joint funding. A close examination of current federal activities can help us understand those aspects of violence development and prevention that might be better addressed jointly and direct funding towards those areas.

More intensive collaboration can be hampered by the lack of a common vocabulary. We need to understand that people from different backgrounds have different vocabularies.
Vocabulary differences need to be described and understood by all parties in order for them to collaborate effectively. A good example is the term "surveillance". Ask a person trained in public health to define it and the response will approximate the official CDC definition of public health surveillance: "the ongoing and systematic collection, analysis, and interpretation of health data in the process of describing and monitoring a health event". ${ }^{4}$ On the other hand, ask someone involved in criminal justice and you might hear something like "the surreptitious collection of information about an individual or organization". Although sometimes comical, conversations between public health and justice agency staff about "improving surveillance of school associated violence" can be frustrating and confusing to the point of breaking down collaborations if we do not make an effort to communicate better.

Developing a shared logic framework is an excellent way to examine differences in vocabulary and define areas of responsibility. In the US, the White House Council on Youth Violence is leading an activity to map federally sponsored projects onto an agreed-upon logic framework of violence causation and prevention. The clusters and gaps identified will point towards areas of possible duplication of effort and areas where we can increase collaboration across agencies.

One example of a cross agency activity that made the effort to develop a shared logic framework is the Safe Schools/Healthy Students Initiative. ${ }^{5}$ This initiative brings together various agencies within the Departments of Education, Justice, and Health and Human Services. Staff from each agency has been assigned to work together on Safe Schools/Healthy Students. Funding streams have been combined. Although it took nearly a year, the definitional and turf issues of collaborative work have been addressed. This exciting new project is funding more than 70 communities across the US to implement activities such as school and community based mental health services, police support in schools, and educational activities directed at reducing school violence and increasing opportunities for healthy childhood development. The pooling of funds also has allowed for the development of a national evaluation and a technical assistance center to support local projects.

It has been more than 30 years since Dr King, who spoke so eloquently in support of non-violence, was himself a victim of homicide. In the years since, many hundreds of interventions have been developed and implemented in isolation from one another. The time has come to recognize that successful violence prevention involves multiple interventions and multiple partners. It is time for those from all fields of study interested in violence prevention to come together and do the hard work of thinking through a comprehensive solution.

LISA C BARRIOS

Division of Adolescent and School Health, Centers for Disease Control and Prevention, 4770 Buford Hwy NE, Mailstop K-33,

Atlanta, GA 30341-3717, USA

email:LIC8@cdc.gov

Kachur SP, Stennies GM, Powell KE, et al. School-associated violent deaths in the United States, 1992 to 1994. FAMA 1996;275:1729-33.

2 Centers for Disease Control and Prevention. Rates of homicide, suicide, and firearm-related death among children-26 industrialized countries. MMWR Morb Mortal Wkly Rep 1997;46:101-5.

3 Division of Adolescent and School Health, Centers for Disease Control and Prevention. Federal activities addressing violence in schools. Fournal of School Health 2000;70:119-40.

4 Centers for Disease Control and Prevention. Guidelines for evaluating surveillance systems. MMWR Morb Mortal Wkly Rep 1988;37(S-5):1-18.

5 US Department of Education, US Department of Justice. Annual report on school safety, 1999. Washington, DC: US Department of Education, US Department of Justice, 1999. URL: http://www.ed.gov/PDFDocs/ InterimAR.pdf. 